\title{
La objeción de conciencia y el diálogo judicial
}

\section{Conscientious Objection and Judicial Dialogue}

\author{
Marc-Abraham Puig Hernández
}

\author{
Autor: \\ Marc-Abraham Puig Hernández \\ Universidad de Barcelona, Espańa \\ marcph@icab.cat \\ https://orcid.org/0000-0002-1960-9903 \\ Recibido: 11-3-2019 \\ Aceptado: 3-9-2019

\section{Citar como:} \\ Puig Hernández, Marc-Abraham, (2020). La \\ objeción de conciencia y el diálogo judicial. \\ Doxa. Cuadernos de Filosofía del Derecho, 43, \\ pp. 313-339. https://doi.org/10.14198/ \\ DOXA2020.43.12 \\ Licencia: \\ Este trabajo se publica bajo una Licencia Creative \\ Commons Atribución 4.0 Internacional.

\section{(c) (i)}

(C) Marc-Abraham Puig Hernández

\begin{abstract}
Resumen
Con la STC 145/2015, de 25 de junio, se dio un paso más respecto a la configuración del alcance general del derecho a la objeción de conciencia. Sin embargo, podemos hacer una lectura positiva y otra negativa de la misma. En este trabajo pretendo sostener: 1) que las consecuencias negativas tienen mayor relevancia porque circunscriben su ejercicio a un supuesto; y 2) que los precedentes de derecho extranjero e internacional hubieran contribuido a asentar las razones de la decisión del TC que ya se desprenden del derecho español. Para ofrecer una explicación teórica del segundo punto, debemos acudir a la propuesta del diálogo judicial como equilibrio reflexivo amplio.
\end{abstract}

Palabras clave: objeción de conciencia; libertad ideológica; no uso del derecho extranjero; diálogo judicial.

\begin{abstract}
SCCD 145/2015 offered a new step towards setting the general scope of the right to conscientious objection and it is possible to highlight positive and negative consequences. In this essay I try to show that: 1) negative consequences have a broader significance as confine its exercise to one assumption; 2) judicial precedents, from foreign and international law, would have contributed to solidify the SCC decision based only on Spanish law. In order to show a theoretical explanation to point two, we must draw on reflexive equilibrium as judicial dialogue proposal.
\end{abstract}

Keywords: conscientious objection; ideological freedom; foreign law non-use; judicial dialogue. 


\section{INTRODUCCIÓN}

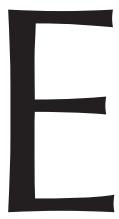

l objetivo del presente trabajo es contribuir a determinar el alcance general del derecho a la objeción de conciencia y al mismo tiempo buscar una explicación teórica relativa al diálogo judicial adecuada al no uso del derecho extranjero dado en la STC 145/2015, de 25 de junio (en adelante STC 145/2015).

En nuestro ordenamiento jurídico, el alcance general de este derecho viene justificado en tanto que una de las posibles manifestaciones de la libertad ideológica. Con la sentencia analizada podemos observar dos cuestiones al respecto: una positiva, la innecesaria intervención del legislador para regular el ejercicio y la protección judicial de este derecho; y una negativa, el impedimento tanto del ejercicio de otros derechos legítimos como del cumplimiento de las obligaciones de terceros mediante el ejercicio de un derecho personalísimo. La cuestión negativa nace de la decisión del TC, que recurre a una argumentación cuestionable, si tenemos en cuenta la confusión generada respecto al alcance de este derecho y el haberse apartado de los precedentes. El TC no hizo uso del derecho extranjero e internacional, que podría haber contribuido a asentar las razones para decidir el caso. Analizaremos como el TC no hizo uso de ellos a fin de contribuir con una explicación novedosa acerca de los modelos teóricos de diálogo judicial, esto es, a través del no uso del derecho extranjero.

La hipótesis que pretendemos defender en este trabajo es, en primer lugar, que las consecuencias negativas de la STC 145/2015 tienen mayor repercusión que las positivas, y con el uso del derecho extranjero e internacional se hubiera contribuido a asentar las buenas razones para decidir el caso que ya se desprenden del derecho español; y, en segundo lugar, que existen argumentos suficientes para sostener que solo uno de los modelos teóricos de diálogo judicial es compatible con ello. Ello implica una serie de opciones metodológicas, tales como:

1) La selección de la fuente y de la temática. Hemos acudido a la STC 145/2015 porque en efecto el TC se aparta del derecho extranjero que habían venido empleando los tribunales ordinarios para decidir el caso y porque la temática no es homogénea en las distintas jurisdicciones, como son la española, la francesa y el foro de Estrasburgo. La temática es la relativa al denominado derecho genérico a la objeción de conciencia, que una vez delimitada según nuestro objetivo, nos será de utilidad para cuestionar los distintos modelos teóricos de diálogo judicial a través de los argumentos empleados por el TC en su decisión.

2) El concepto de derecho (genérico) a la objeción de conciencia. Los medios propuestos en las normas para alcanzar los fines exigidos por el Derecho (obligaciones) generan un conflicto insuperable de conciencia, compuesto por el mínimo ético contenido en un deber concreto que respalda la mayoría, a través del legislador, y por el mínimo ético que defiende el ciudadano en minoría para cumplir con el ordenamiento jurídico. Se plantea de esto modo la exención a un deber concreto para respetar la libertad de conciencia del individuo. Una excepción que confirma la regla de cumplir con el resto del ordenamiento. 
3) Una definición previa de los modelos teóricos de diálogo judicial. La doctrina jurídica ha discutido principalmente sobre los siguientes tres modelos:

a) Modelo de la resistencia. De acuerdo con este modelo, los materiales jurídicos extranjeros nunca pueden ser relevantes para interpretar la propia constitución, pues ponen en entredicho el autogobierno de los tribunales estatales.

b) Modelo de la convergencia. Se aboga por que las prácticas constitucionales estarían destinadas a converger mediante el uso del derecho internacional y de otras jurisdicciones.

c) Modelo de la imbricación. En este tipo, el derecho extranjero o internacional no se trata como presuntamente vinculante y, sin embargo, los tribunales no excluyen las fuentes y la experiencia del derecho extranjero para tomar decisiones.

De acuerdo con las coordenadas en las que se circunscribe esta temática, el trabajo lo estructuramos de la siguiente manera: 1) por una síntesis del caso resuelto en la STC $145 / 2015$ y unas consideraciones previas al alcance general del derecho a la objeción de conciencia; 2) por las consecuencias de hallarnos ante un derecho personalísimo; y 3) por el no uso del derecho extranjero e internacional en la decisión del TC.

\section{LA STC 145/2015 Y EL ALCANCE DEL DERECHO A LA OBJECIÓN DE CONCIENCIA}

En la STC 145/2015 se discute el alcance general del derecho a la objeción de conciencia. Veamos, en primer lugar, qué hechos dieron origen a este pronunciamiento para así, en segundo lugar, pasar a observar algunas de las consideraciones hechas al alcance de este derecho.

\section{El caso del farmacéutico objetor}

En la STC 145/2015 se discutió el ejercicio del derecho genérico a la objeción de conciencia de un farmacéutico. Los tribunales ordinarios habían negado la posibilidad de ejercer este derecho para eximirse del cumplimiento del deber de disponer de cierta medicación que viene fijada por la legislación andaluza. Este incumplimiento repercute sobre otro deber, a saber, la obligación del farmacéutico de dispensar la medicación prescrita legalmente o solicitada por el paciente y que prohíben los precedentes.

El TC contempló el ejercicio de este derecho apartándose de las decisiones de los tribunales ordinarios, que se apoyaron en las decisiones del TEDH y los tribunales franceses sobre un caso similar en Francia. En tanto contemplaron aquellas decisiones, las sentencias de los tribunales ordinarios espańoles, la del TEDH y las de los tribunales franceses coincidieron en un mismo sentido: los farmacéuticos no podrían negarse a 
dispensar la medicación por razones de conciencia. Sin embargo, el TC entendió que sí puede eximirse de disponerlos.

Prestaremos ahora atención al caso que da lugar al pronunciamiento del TC, al que recurriremos asiduamente a lo largo del trabajo. Los hechos que dan lugar a esta sentencia pueden resumirse de la siguiente manera.

Un hombre solicitó preservativos en una farmacia del centro de Sevilla, pero el farmacéutico no se los dispensó al no tener en el almacén. La reclamación administrativa del cliente dio lugar a una inspección en la farmacia. Y con la inspección se evidenció que el establecimiento no disponía ni de preservativos ni del principio activo levonorgestrel 0,750 mg. (comúnmente denominado «la píldora del día siguiente»).

El motivo que arguyó el farmacéutico cotitular del establecimiento para no disponer de ellos consistía en ser objetor respecto a los medicamentos con efectos abortivos. La Administración sancionó a dicho farmacéutico, persona distinta a quien no dispensara los preservativos, bajo el motivo de haber contravenido la Ley andaluza que establece el listado de medicamentos que deben disponer las farmacias. Dicho farmacéutico hizo valer su condición de objetor amparándose en los Estatutos del Colegio de Farmacéuticos de Sevilla y en el Código Deontológico de su profesión, tanto frente a la Administración como ante los tribunales ordinarios, quienes sistemáticamente no reconocieron el derecho a la objeción de conciencia. La decisión se fundamentó en concordancia con la STEDH de 2 de octubre de 2001, asunto Pichon et Sajous vs. Francia y con las decisiones de los tribunales franceses que originaron el pronunciamiento del TEDH ${ }^{1}$.

Finalmente, el TC otorgó el amparo y reconoció la objeción de conciencia como contenido esencial del derecho fundamental a la libertad ideológica. A tales efectos, se centró en la disposición de los medicamentos en el almacén y no en la dispensación, como venían haciendo el resto de tribunales. Declaró haber derecho respecto al principio activo levonorgestrel $0,750 \mathrm{mg}$., no así respecto a los preservativos: aceptó que las convicciones éticas del farmacéutico contra los posibles efectos antiabortivos del fármaco justifican la exención del deber, mientras que en el caso de los preservativos no observaríamos los efectos antiabortivos, sino los de anticoncepción e higiene ${ }^{2}$.

1. En el caso discutido en estos precedentes, dos farmacéuticos franceses se negaron a dispensar medicamentos anticonceptivos prescritos legalmente. Como puede verse en González SAquero (2008: 243-282), este criterio coincide con el que habían seguido los tribunales españoles en la interpretación de los derechos de los farmacéuticos.

2. En nuestra opinión, no hay justificación para esta diferencia. El fármaco levonorgestrel 0,750 mg. es igualmente un método anticonceptivo si advertimos que su finalidad es la de impedir la concepción en las horas siguientes al coito y no así habilitar un efecto abortivo, que técnicamente requiere desechar un embrión. En este caso, al impedir el contacto entre gametos (o su posible desarrollo celular), no se da lugar a la formación de ese embrión y el aborto carecería de objeto. El fármaco y el profiláctico tienen idéntica finalidad anticonceptiva, pero según nuestro ordenamiento jurídico nos encontramos ante dos métodos que reciben diferente trato: el primero es inconstitucional mientras que el segundo es constitucional. 


\section{Consideraciones acerca del alcance general del derecho a la objeción de conciencia}

El alcance general del derecho a la objeción de conciencia no es una cuestión pacífica para los juristas ${ }^{3}$. A continuación, vamos a prestar atención a las normas que habilitan ejercer este derecho a tenor de la jurisprudencia del TC. Para ello, encontramos necesario destacar, al menos, los siguientes aspectos: que el derecho a la objeción de conciencia tiene carácter genérico por su vinculación con el derecho fundamental a la libertad ideológica y que de dicho vínculo procede el denominado límite de orden público.

\section{i. Ejercicio del derecho en virtud de la libertad ideológica}

En nuestro ordenamiento jurídico, la objeción de conciencia es una de las posibles manifestaciones de la libertad ideológica proclamada en el artículo 16.1 CE, de acuerdo con una reiterada jurisprudencia constitucional ${ }^{4}$. El derecho "genérico" a la objeción de conciencia es un derecho que no se encuentra expresamente recogido en el texto constitucional, sino que se vincula necesariamente con el respeto de esta libertad. De ahí que se haya afirmado que de la CE se derivan dos tipos explícitos (la objeción de conciencia al servicio militar y la cláusula de conciencia de los profesionales de la comunicación, recogidos en los artículos 30.2 y 20.1.d respectivamente) y uno implícito (a través de la manifestación de la libertad ideológica del 16.1) de objeción de conciencia5.

Al contener tres modos de objeción de conciencia (dos explícitos y uno implícito), podemos realizar una distinción categórica entre dos tipos de ejercicio. Para Prieto SANChís (2013) hay lugar a una objeción a priori (regulada, como en el caso del servicio militar) y otra a posteriori (no regulada), o implícita, donde la objeción sería considerada por los jueces una vez se incumple el mandato y como justificación de la conducta contraria a la exigida por el ordenamiento jurídico.

En perspectiva teórica, necesitamos la existencia de una norma que autorice incumplir un determinado deber por parte del sujeto ya sea con carácter general o para casos particulares. En efecto, se presupone la existencia de una norma que permita la excepción a determinadas obligaciones o a soportar la sanción por su incumplimiento ${ }^{6}$.

3. Podemos ver posturas contrapuestas, por un lado, en las obras de González Pérez, 2017 y DíEz-Picazo Giménez, 2013 y, por otro lado, en Navarro-Valls y Martínez-Torrón, 2011, Ruiz Miguel, 1986-1987: 399-421 y Gascón ABELlán, 1990.

4. Vid., entre otras: SSTC 15/1982, de 23 de abril; 53/1985, de 11 de abril; 160/1987, de 27 de octubre; $321 / 1994$, de 28 de noviembre. Las dos últimas sentencias son igualmente controvertidas, pues se confunde objeción de conciencia con otras figuras de insumisión al ordenamiento. En la jurisprudencia citada, el TC admite el ejercicio de la objeción de conciencia fuera de los casos expresamente previstos por la CE, aunque su ejercicio parece estar relegado a la intervención del legislador, cuestión que quedó zanjada con la STC 145/2015 que discutimos en este trabajo. Otra decisión del TC en esta línea es el ATC 1227/1988, de 7 de noviembre.

5. Para un examen más extenso de esta cuestión, vid. Escobar Roca, 1993: 203 y ss.

6. Prieto Sanchís, 2013: 286. 
Veámoslo desde la lógica de la aplicabilidad y la pertenencia de la objeción de conciencia al sistema normativo. Para este autor, la presuposición de esa norma estaría indicando, de forma resumida, que a un caso individual, instancia del caso genérico $\mathrm{C}$, le es de aplicación la norma $\mathrm{N}$ (derecho a la objeción de conciencia) del sistema $\mathrm{S}$ (nuestro ordenamiento jurídico) si y solo si otra norma N1 (por ejemplo, la CE) perteneciente al mismo sistema $\mathrm{S}$ indica que $\mathrm{N}$ resulta de aplicación a los casos individuales que son instancias de $\mathrm{C}^{7}$.

De igual modo que cualquier otra norma, el derecho a la objeción de conciencia igualmente requiere que N1 (una norma perteneciente a S) permita la exención al cumplimiento del deber: si y solo si otra norma N1 perteneciente a $\mathrm{S} 1$ «indica» que resulta de aplicación.

En nuestro ordenamiento jurídico, N1, la norma perteneciente al ordenamiento jurídico $S$ y que indica aplicar este derecho, es la CE. Y, en efecto, de la propia CE entendemos que el cumplimiento de determinadas obligaciones puede suponer una afrenta a la libertad ideológica, o de conciencia, según la terminología que empleemos. De existir estas libertades en nuestro ordenamiento jurídico y de que su contenido se garantice constitucionalmente, sería jurídicamente imposible vincular la objeción de conciencia con la desobediencia civil o cualquier otra figura que suponga la insumisión.

A diferencia de otras figuras, la objeción de conciencia constituye plenamente una cuestión jurídica. La exención del cumplimiento del deber constituye un dilema de contradicciones jurídicas que los tribunales deben resolver, al existir razones tanto para hacer cumplir la ley como para aceptar la exención y respetar así la libertad de conciencia del individuo.

Con lo expuesto, detengámonos a realizar dos observaciones. La primera, al ser una cuestión estrictamente jurídica, y que por tanto no implica entrar en ninguna disputa entre Derecho y Moral, su planteamiento en sede judicial presentó la exigencia de ser resuelta pese a no encontrarse expresamente regulada. Y, la segunda, los tribunales debían decidir si dicha cuestión se resolvía mediante la figura de los derechos y obligaciones.

En el aspecto teórico, tanto el TC como el TEDH tuvieron que dar respuesta al siguiente problema configurado por dos conductas incompatibles entre sí según su carácter deóntico:

Por un lado, es obligatorio cumplir con el ordenamiento jurídico. El cumplimiento del Derecho implica que los destinatarios de las normas en algún grado adecúan su comportamiento al que estas exigen. En caso de no hacerlo, se les motiva, obliga o incluso sanciona por ello ${ }^{8}$.

Por otro lado, está prohibido violar los derechos fundamentales. Todo derecho supone una pretensión legítima y, en este caso, el cumplimiento de un deber conlleva

\footnotetext{
7. En cuanto a la pertenencia y aplicabilidad de las normas, seguimos la obra de NAVArRo y Moreso, 1996: 119-139.

8. Tomamos la noción de cumplimiento de Navarro, 1990: 88-91.
} 
la violación de otro derecho como el de la libertad ideológica, que goza de las mayores garantías según nuestro ordenamiento jurídico.

Se plantea la justificación de optar entre lo obligatorio, según la norma N1, y lo prohibido, según la norma N2. La interpretación sobre la que convergen el TC y el TEDH es que, entre habilitar el cumplimiento de la obligación o proteger los bienes sobre los que está prohibido inmiscuirse, del segundo nace el derecho para acogerse al mínimo ético que el ciudadano respalda para cumplir con el resto del ordenamiento. Consecuentemente, ambos tribunales convergen en que el derecho genérico a la objeción de conciencia constituye una de las posibles manifestaciones de esa libertad. Y, además, es un derecho "genérico» en tanto la prohibición relativa al respeto de un derecho fundamental puede materializarse en cualquier situación jurídica. Coinciden, en definitiva, en un derecho que expresamente no se encuentra reconocido ni en el derecho nacional ni en la norma internacional de referencia, sino que nace de la coacción al individuo en su ámbito garantizado de libertad.

\section{ii. La innecesaria intervención del legislador}

La STC 145/2015 tiene una consecuencia positiva respecto al alcance general del derecho a la objeción de conciencia: la innecesaria intervención del legislador para regular su ejercicio, hecho habitualmente referido por interpositio legislatoris. Podemos afirmar que, una vez otorgado el amparo, estamos en presencia de un derecho constitucional, en otras palabras, ante una de las manifestaciones del derecho fundamental a la libertad ideológica que se garantiza en sede judicial.

De esta consecuencia podemos encontrar razones para dar un sentido diferente al límite «de orden público definido por ley» del artículo 16.1 CE, de aplicación a la libertad ideológica y, por tanto, al alcance genérico de este derecho. Para Prieto Sanchís y Gascón Abellán, el límite de este derecho no es una cuestión sencilla de acotar, porque el orden público es un concepto impreciso, por caber otro tipo de limitaciones a este derecho más allá del orden público y porque la libertad de conciencia, al mismo tiempo, supone un límite para el orden público. Sin embargo, entre las observaciones acerca del orden público de estos autores no encontramos articulada una referencia a la característica que exige la propia norma: que esté definido por ley.

Se ha defendido que el orden público consiste en un concepto jurídico indeterminado el cual en efecto puede determinarse en el caso concreto mediante algún proceso capaz de desembocar en la solución correcta ${ }^{9}$. Aparentemente, esta doctrina desoye que el orden público constituye una noción abierta a concepciones plurales de moralidad y juicios de valor como se desprende de la jurisprudencia constitucional sobre el artículo 16.1 CE. Ahora bien, tampoco debemos suponer que el horizonte axiológico de una constitución tenga que ser indefinido por el hecho de ser plural. Más bien el orden

9. García de ENTErría, 1974: 35. 
público se situaría entre las dos posturas: la predeterminación en el caso concreto y la concepción abierta, propia de una sociedad plural. Y el instrumento jurídico que ofrezca solidez a un concepto de orden público que da lugar a concepciones tan contrapuestas no puede ser otro que la ley. El propio ordenamiento jurídico es el que nos define las coordenadas de ese orden.

En una situación concreta, acudiremos al régimen jurídico que regula esa determinada situación, verbigracia, las normas contractuales o el Derecho Administrativo. En ausencia del régimen jurídico específico de una situación, el propio ordenamiento nos exige el máximo respeto de los derechos fundamentales y de los principios y valores constitucionales. El orden público «definido por ley» no puede significar otra cosa que la debida observancia del ordenamiento jurídico, una suerte de remisión al Derecho imperativo propio de toda situación jurídica y, en su ausencia, al contenido que siempre debe respetarse, y que por tanto es igualmente imperativo.

Si bien este límite de orden público nos recuerda que la libertad ideológica se ejerce en potencial concurrencia con otros derechos y obligaciones de carácter imperativo, así la propia CE nos estaría indicando la necesidad de ponderar la situación, y al mismo tiempo nos sugiere que el legislador haya determinado el régimen jurídico de las relaciones intersubjetivas. Esto es, en lugar de que el juez esclarezca en cada caso qué normas imperan en un ámbito jurídico, el orden público «definido por ley» constituye un mandato al legislador para que efectivamente lo defina.

De ser cierto que el legislador tiene la potestad, y en virtud de lo expuesto podemos afirmar también la obligación, de definir el marco jurídico de una relación, la interpositio legislatoris no se proyecta como un límite al alcance del derecho genérico a la objeción de conciencia, sino al legislador, a fin de determinar el régimen jurídico de cualquier relación.

A nuestro modo de ver, es ahora cuando adquieren relevancia las posturas de Gascón Abellán y Prieto Sanchís cuando afirman que los límites del derecho a la objeción de conciencia son los límites propios de todo derecho fundamental. Dicho límite procede de haber determinado con qué derecho entra en conflicto nuestro derecho fundamental. De ahí la necesidad de un orden público definido normativamente: según las circunstancias particulares del caso, la aplicación de uno de los dos límites (el que un derecho le supone a otro mutuamente) debe desplazar, o excepcionar, la eficacia del otro, como defienden los autores.

Finalmente, observamos que esta explicación concuerda con el amparo otorgado en la STC 145/2015. El derecho a la objeción de conciencia se ponderó con las normas imperativas que el legislador andaluz había establecido para garantizar los derechos constitucionales básicos como el acceso a la medicación prescrita que se sigue de la jurisprudencia relativa al artículo 43.2 CE. En definitiva, la intervención del legislador no es necesaria para garantizar el ejercicio del derecho a la objeción de conciencia, sino para definir el régimen jurídico de los ámbitos en que pueda acontecer. 


\section{UN DERECHO PERSONALÍSIMO}

En este epígrafe analizaremos por qué estamos en presencia de un derecho personalísimo, si ello impide un ejercicio colectivo del mismo y si esta explicación concuerda con la argumentación del TC.

En primer lugar, observaremos, a través de un ejemplo de Derecho comparado, las razones para justificar el ejercicio colectivo de un derecho personalísimo. $\mathrm{Y}$, en segundo lugar, veremos que, al distinguir entre dispensación y disposición de medicamentos, el TC creó un verdadero embrollo jurídico acerca del ejercicio de este derecho.

\section{El derecho personalísimo y la posibilidad de su ejercicio colectivo}

Con la sentencia del Tribunal Constitucional chileno de 2 de agosto de 2017 se despenalizaron en Chile tres causas de interrupción del embarazo (inviabilidad del feto, peligro para la vida de la madre y embarazo por violación) y se estableció la denominada «objeción institucional» de los centros hospitalarios ${ }^{10}$, que permite tanto a los cirujanos como al equipo médico formular objeción en la participación en la interrupción del embarazo. Se abrió el debate acerca del ejercicio colectivo del derecho a la objeción de conciencia.

Este derecho nos sitúa ante un conflicto personalísimo que vinculamos prima facie a la persona humana. Sin embargo, según el derecho a la libertad ideológica, las empresas pueden adoptar un ideario y, además, tienen la facultad de difundirlo a través de imponer ciertas obligaciones laborales, función característica de las empresas ideológicas o de «tendencia»" ${ }^{11}$. De ahí aceptamos un ejercicio colectivo de este derecho.

Debemos advertir un cierto grado de moralidad en las empresas puesto que, en su ausencia, una empresa no podría adoptar una determinada ética empresarial, tampoco difundirla, ni podríamos incluso impetrar la responsabilidad criminal de una corporación por delinquir, al ser un elemento esencial del Derecho Penal la voluntad de cometer el delito. Si no aceptáramos que las empresas pueden adoptar un ideario, tampoco podríamos criminalizarlas ni utilizarlas para perseguir fines ideológicos, como la difusión de una religión en el caso de los centros docentes privados. En definitiva, si son sujetos para responder penalmente por ilícitos, también lo serán para acogerse

10. Derecho que modifica el artículo 119 ter del Código Sanitario chileno.

11. En nuestro ámbito doctrinal, el término «empresa ideológica» tiene la primera referencia en APARICIO Tovar, 190: 269-306. En cuanto al ámbito judicial, si prestamos atención a la primera sentencia del TC que incorporó el concepto de empresa ideológica, encontraríamos motivos para desestimar las razones esgrimidas en la sentencia chilena. En la STC 106/1996, de 12 de junio, que destacaba la ausencia por entonces de una normativa estatal relativa a empresas y organizaciones ideológicas, se explicó que, a diferencia de un centro educativo, un hospital religioso no entraría dentro de esta categoría debido a que la principal función de este centro sería la sanitaria por encima de la función ideológica. Y, en el ámbito normativo, la primera referencia vino posteriormente con el artículo 4 de la Directiva 2000/78/CE y la Ley 62/2003, de 30 de diciembre, traspositiva de esa directiva. 
al ideario que han adoptado legalmente para realizar las actividades empresariales que dirigen a la consecución de un fin ideológico. Y una sociedad, una institución, o ese centro hospitalario o docente, es una agrupación de personas que pueden acogerse conjuntamente al ideario que las une en las actividades que llevan a cabo. Luego, no nos debe extrañar la posibilidad del ejercicio colectivo del derecho a la objeción de conciencia cuando surge un conflicto ético con su ideario.

Ahora bien, diferente es el supuesto en que acogerse a este derecho, para exigir el respeto a su ideario, supone el impedimento para que terceras personas ejerzan derechos legítimos. En el caso chileno, el ejercicio «institucional» solamente repercute en determinados centros concertados: los centros públicos tienen la obligación inexcusable de cumplir con el ordenamiento por la neutralidad ideológica de las instituciones públicas, no así los centros de tendencia que tienen una ética garantizada por el propio ordenamiento a través de la libertad ideológica o de pensamiento. A los centros concertados debe acudirse de propia voluntad y solicitar los servicios obstétricos o ginecológicos. En este caso, el ejercicio «institucional» de la objeción de conciencia no impide el derecho a interrumpir el embarazo por alguna de las tres causas reconocidas en la sentencia, dado que puede acudirse a un centro público y verse satisfecho.

En cambio, en el caso de la STC 145/2015 no podemos hacer valer estas razones. Encontramos que, al menos, son dos los motivos que nos impiden la misma justificación que en el caso chileno: la cotitularidad del establecimiento farmacéutico y los casos en que la farmacia esté de guardia.

Por un lado, a diferencia de las empresas ideológicas, en el caso del farmacéutico objetor, la titularidad del establecimiento es compartida. Junto a este farmacéutico existe otro titular del mismo. Cuando el objetor hizo valer sus convicciones, alegó haber constatado su condición en el registro del colegio de farmacéuticos. No era la ética empresarial o el ideario del establecimiento lo que invocó, sino su propia condición. No hay ninguna prueba de que el establecimiento siguiera una ideología determinada, sino que uno de los cotitulares dejó constancia de sus convicciones. De ahí que la exención al deber, en cualquier caso, pudiera justificarse para este farmacéutico y no así para el conjunto del establecimiento.

Y, por otro lado, tampoco se cumple la condición de poder dispensar los medicamentos en otra farmacia cuando el establecimiento del objetor esté de guardia. En la sentencia chilena, los centros obstétricos concertados no impiden que cualquier ciudadano acuda a un centro público. Queda en una decisión de los particulares acudir a uno u otro. Sin embargo, en el caso del farmacéutico sevillano, cuando el establecimiento sea designado de guardia quedaría eliminaría la posibilidad de acudir a otra farmacia cercana. En ese caso, dicho establecimiento no dispondrá del mínimo de medicamentos exigido por la normativa andaluza y el derecho a la salud quedará temporalmente desprovisto de garantías.

La decisión abre una serie de interrogantes, tales como: 
a) No se fundamentó qué habilita el ejercicio de un derecho fundamental. En el amparo, el TC hizo valer que cualquier persona puede acudir a otra farmacia cercana para obtener los medicamentos. Como hemos visto, no puede ser el presupuesto que justifique la aplicación de un derecho fundamental siempre y cuando impida ejercer otros derechos fundamentales o que se cumplan otras obligaciones.

b) Se creó confusión en torno a la estructura y a la naturaleza de este derecho al crear una nueva norma. En la STC 145/2015 coincide la titularidad del derecho en la figura del farmacéutico y la del establecimiento de farmacia. El objetor es el farmacéutico cotitular, sin embargo, la objeción repercute sobre la obligación de disponer del otro cotitular y la del resto del personal de la farmacia, quienes, en caso de querer cumplir con el ordenamiento, por ejemplo, al estar de guardia, deberían objetar a la norma que ahora les impone el deber de respetar las creencias del farmacéutico cotitular. Carece de justificación tener que objetar para cumplir con la obligación jurídica previamente objetada. La decisión del TC debería eximir del cumplimiento de una obligación, la del farmacéutico objetor, sin que ello creara una nueva obligación, una nueva norma, contra la que otros sujetos nuevamente deban objetar.

c) Se apartó de las decisiones precedentes de los tribunales ordinarios y, especialmente, de la decisión del TEDH sin ofrecer mayor justificación que el cambio no fundamentado de presupuesto. Ciertamente, disposición y dispensación son presupuestos distintos, con deberes y obligaciones diferenciadas. No obstante, existe una relación entre ambas que no puede ignorarse en la decisión, y que trataremos de exponer a lo largo del siguiente epígrafe.

En síntesis, el amparo al farmacéutico objetor impide el ejercicio de otros derechos legítimos y, al mismo tiempo, el cumplimiento de las obligaciones impuestas por el ordenamiento jurídico a terceras personas. Y ello es porque el derecho personalísimo de un farmacéutico se impone al resto del personal de farmacia tras diferenciar entre dispensación y disposición de los medicamentos. Veamos detenidamente la relación entre ambos conceptos y algunas consecuencias de la decisión del TC relativas al ejercicio colectivo de este derecho.

\section{Dispensación, disposición y la relación entre ambos conceptos}

Para otorgar amparo, el TC diferenció entre la objeción a dispensar y a disponer medicamentos. De esta manera, se apartó de los precedentes que impedían garantizar este derecho. Ahora bien, el TC obvió que entre estos dos supuestos se da una relación lógica necesaria que impediría desoír las decisiones anteriores.

En la relación entre ambos supuestos, debemos asumir que, para poder dispensar la medicación es un requisito necesario disponerla en el almacén del establecimiento. Esto es, si no disponemos de ella ( $\neg \mathrm{D} 1)$, entonces no podemos dispensarla $(\neg \mathrm{D} 2)$. Y, al 
revés, si la dispensamos (D2) es porque hay existencias en el almacén (D1). Entonces, parece argumentable que todo lo que es condición necesaria de lo obligatorio, es también obligatorio. Una vez aceptado este principio, estaríamos en condiciones de afirmar que, si es obligatorio dispensar cierta medicación, también es obligatorio tenerla en el almacén, esto es, disponer de ella.

$\mathrm{Si}$ observamos los precedentes, como está prohibido $\neg \mathrm{D} 2$ por motivos de conciencia, es lógico suponer que los mismos motivos están prohibidos para su condición necesaria: estaría también prohibido $\neg \mathrm{D} 1$. Sin embargo, el TC no observó el principio de esta relación y entendió que los precedentes únicamente prohíben no efectuar la dispensación $(\neg \mathrm{D} 2)$.

Por consiguiente, en la relación entre $\mathrm{D} 1$ y D2, la primera es una condición necesaria de la segunda, pero solo está prohibido $\neg \mathrm{D} 2$. De ahí obtenemos una serie de posibilidades:

En primer lugar, si no hay existencias disponibles por motivos de conciencia $(\neg \mathrm{D} 1)$, cualquier posibilidad de dispensar queda suprimida ( $\neg$ D2).

En segundo lugar, si hay existencias disponibles (D1), presumiblemente van a ser dispensadas con independencia de los motivos de conciencia (D2), porque es obligatorio D2 al estar prohibido $\neg \mathrm{D} 2$.

Pero cabe una tercera posibilidad. Con existencias disponibles (D1) cabe que no sean dispensadas por motivos de conciencia $(\neg \mathrm{D} 2)$.

Configuramos la tabla lógica de la siguiente manera:

$$
\begin{aligned}
& \text { 1. } \mathrm{D} 1 \wedge \mathrm{D} 2 . \\
& \text { 2. } \mathrm{D} 1 \wedge \neg \mathrm{D} 2 . \\
& \text { 3. } \neg \mathrm{D} 1 \wedge \neg \mathrm{D} 2 .
\end{aligned}
$$

Vemos que, en atención al principio señalado, no es posible una cuarta posibilidad: $\neg \mathrm{D} 1$, pero sí D2. Es materialmente imposible que si no hay medicamentos los podamos dispensar.

Según el TC, los precedentes harían referencia a la situación 2 de la tabla: no caben motivos de conciencia para no dispensar las existencias; el TC entiende que esta prohibición ocurre en relación a si hay existencias en el almacén. Pero ello es incoherente con el hecho de que la existencia en el almacén sea condición necesaria de la prohibición: si está prohibido $\neg \mathrm{D} 2$ por motivos de conciencia entonces es obligatorio D2, y aunque existan motivos de conciencia, no podrían conducirnos al resultado $\neg \mathrm{D} 2$, por ejemplo, al darse en D1. Sin embargo, el TC decide que sí proceden esos motivos y da lugar a la situación 3.: $\neg \mathrm{D} 1 \mathrm{y}$, por tanto, $\neg \mathrm{D} 2$.

En definitiva, según la lógica que subyace a la relación entre D1 y D2, el TC tomó una decisión contradictoria, haciendo posible lo que era imposible. $\mathrm{O}$ es verdadero $\neg \mathrm{D} 2$, o es verdadero D2, porque una implica la falsedad de la otra.

En la decisión del TC termina por confundirse el ejercicio de un derecho personalísimo con el ejercicio colectivo del mismo. Cuando afirmamos que la titularidad del derecho a la objeción de conciencia pertenece exclusivamente al objetor, no descartamos 
que un derecho personalísimo pueda llegar a ejercerse colectivamente. Ahora bien, en el caso de la STC 145/2015, la decisión que toma el TC es una solución válida únicamente para el objetor. Tanto el otro cotitular como el resto del personal de farmacia también tienen el mismo derecho constitucional. De no ser así, el TC debería haber justificado que la ideología de un solo individuo configuraba la ética o el ideario adoptado por el establecimiento.

Es por ello que $\neg \mathrm{D} 1$ es una solución para el objetor. Constituye la exención de su deber personalísimo, pero su efecto repercute sobre el resto del personal del establecimiento, que no puede cumplir con sus obligaciones legales: ni disponer de las existencias que exige la Junta de Andalucía ni dispensar el producto farmacéutico solicitado por los clientes. La exención del cumplimiento del deber de un farmacéutico, propiamente su derecho a la objeción de conciencia, aquí se ha visto convertida en la imposición de una concepción ideológica particular sobre el resto de ciudadanos, quienes no tienen la posibilidad de cumplir con el ordenamiento jurídico o hacer valer una concepción contraria a la del objetor.

$Y$ con ello nos encontramos ante un escenario novedoso para nuestro ordenamiento jurídico: un grupo de personas legitimadas por el TC para no cumplir con el ordenamiento jurídico, aunque ellas mismas quisieran. Es la consecuencia de declarar haber lugar a la objeción respecto a un deber de titularidad compartida.

Para no haber dado lugar a este desorden legal podría haberse prestado atención a otra exención igualmente derivada del presupuesto de la disposición que penaliza la norma andaluza. Nos referimos a la exención de la sanción resultante de aplicar la norma, cuya imposición recaía únicamente sobre el objetor, en lugar de dejar sin efecto la propia norma para un selecto grupo de farmacéuticos.

De haber sido así, el farmacéutico objetor habría hecho valer igualmente sus motivos de conciencia, al haberse eximido de la sanción y el resto del personal de farmacia hubiera podido cumplir con las obligaciones impuestas por el ordenamiento jurídico. Claro que, de este modo, hubiera sido necesario haber considerado los precedentes para posteriormente eximir al farmacéutico de la sanción.

\section{El recurso a la argumentación por analogía}

En el caso que nos ocupa, el TC entendió que procedía objeción al deber de disposición, pero recurrió a un argumento analógico. Al respecto, podemos observar que, al hacer valer este tipo de argumento, el caso no debería tener atribuida alguna solución normativa. Sin embargo, en efecto la tiene por la norma andaluza y por el artículo 16.1 $\mathrm{CE}$, las normas que designan las conductas incompatibles, y por tanto la exención al deber debería justificarse, en cualquier caso, sobre el derecho a la objeción de conciencia y no sobre un caso análogo. Si existe el derecho y procede el amparo, la sentencia debe justificarse conforme al objeto de este derecho. En principio no hay razón para 
atribuirle la solución normativa de otro supuesto, lo que nos situaría frente a una laguna normativa y nos llevaría a concluir que no habría norma para otorgar amparo.

Pese a no darse este tipo de laguna, en el voto concurrente de la sentencia vemos suficientes indicios como para identificar una laguna axiológica; puede entenderse que tanto el artículo 16.1 CE como las garantías de la libertad ideológica obligaban al legislador andaluz a contemplar una excepción que no se llevó a cabo. Sin embargo, creemos que también existen razones para rechazar esta justificación. Ante una laguna axiológica ${ }^{12}$, debe sostenerse una tesis de relevancia de acuerdo con una propiedad del caso. Respecto a los medicamentos anticonceptivos creemos que no procedería. El TC debería justificar por qué la sociedad en su conjunto considera moralmente incorrecto usar este tipo de fármaco, debiendo demostrar la relevancia de sus efectos abortivos, lo que configuraría un hecho distinto a decidir si en un caso particular las garantías de las convicciones de un individuo pueden prevalecer sobre una norma imperativa. De ser así, el contexto argumentativo al que remite una laguna axiológica exigiría probar la existencia real del efecto abortivo y la postura de la sociedad. En primer lugar, habría que acudir a argumentos técnicos para demostrar que el conjunto de células previo a un blastocito, que se desarrolla a partir del quinto o sexto día de fecundarse el óvulo, constituye el objeto de un aborto. Y, en segundo lugar, que la sociedad lo considera incorrecto; se asumiría que la postura de la sociedad puede resumirse en una posición que descalifica este fármaco. Pero ello sería incoherente con otras prácticas como la investigación genética a través de la donación de gametos o las técnicas de reproducción asistida, dado que los óvulos implantados están ya fecundados, mientras que en el caso del fármaco anticonceptivo ni siquiera terminan desechándose óvulos necesariamente fecundados. En definitiva, rechazaríamos este argumento porque si las técnicas y el tratamiento de estructuras celulares en estadios posteriores, más desarrollados, son moralmente aceptables, no sería procedente justificarlas como moralmente incorrectas para el caso de estadios menos desarrollados como el de los medicamentos anticonceptivos.

El TC consideró que un caso resuelto en 1985 presentaba similitudes al que debía resolver entonces y decidió emplear un argumento analógico ${ }^{13}$. En este caso, la semejanza relevante del caso para establecer la analogía fue el presupuesto antiabortista. Si en 1985 se decidió que cabía la objeción de conciencia por motivos antiabortistas, en el caso del farmacéutico cabía atribuirle la misma solución normativa. Claro es que esta interpretación extensiva no está exenta de reparos.

En primer lugar, y como acabamos de advertir, por la contradicción entre aceptar el amparo, despejando las dudas acerca de la necesidad de que intervenga el legislador porque la objeción de conciencia es parte del contenido esencial del derecho fundamental a la libertad ideológica, y después recurrir a un argumento analógico empleado para casos no regulados. O el derecho está garantizado por la CE o no lo está. Por más

12. En lo relativo a las lagunas axiológicas hemos seguido a Alchourrón y Bulygin, 1971.

13. En lo referente al argumento analógico hemos seguido la obra de AtienZA, 1986. 
vueltas que le demos, lo primero nos lleva a motivar por qué prevalece el derecho del farmacéutico y lo segundo a admitir que no existe el derecho a objetar de ese farmacéutico, lo que previamente hubiera impedido aceptar el ruego de amparo.

En los votos particulares de la STC 145/2015 se puso de manifiesto que el TC creó una nueva norma al decidir que había lugar para la objeción de conciencia. Tal vez esta crítica no sea del todo acertada si asumimos que este derecho es parte del contenido esencial del derecho fundamental a la libertad ideológica. De ser así, el TC estaría aplicando un derecho a un caso que no se había planteado anteriormente; el TC estaría sentando un precedente, no así creando una nueva norma.

Ahora bien, sí que supone una nueva norma en tanto con el argumento analógico se aplica una solución normativa a un supuesto similar no previsto en el ordenamiento jurídico. Como hemos advertido, el derecho efectivamente está previsto en nuestro ordenamiento a través de la libertad ideológica, pero el TC no explicó qué fundamenta el ejercicio de este derecho, sino que, con esta argumentación, lo vinculó a un único supuesto, el antiabortista.

Y, en segundo lugar, en cuanto al propio argumento analógico, si una solución normativa estaba prevista expresamente para los médicos, caben dudas sobre la identidad de razón que extiende este derecho al farmacéutico cuando ya existía un precedente sobre ese colectivo y a través del cual llegaríamos a la decisión contraria.

En conclusión, si pretendemos realizar la fundamentación del derecho genérico a la objeción de conciencia a partir de la última decisión del TC nos hallamos ante una situación confusa. $\mathrm{Ni}$ es acorde a las decisiones de otras democracias constitucionales ni se justifica en la libertad que lo habilita ${ }^{14}$.

\section{EL NO USO DEL DERECHO EXTRANJERO E INTERNACIONAL}

La hipótesis que estamos tratando de defender en este trabajo es que al hacer uso del derecho extranjero e internacional se hubiera contribuido a no crear el estado actual de confusión acerca del derecho a la objeción de conciencia. De haber considerado los precedentes, el TC hubiera ofrecido mayor consistencia a su decisión, aunque finalmente hubiese decidido en un sentido contrario a los mismos.

Entre los precedentes encontramos derecho extranjero, las decisiones de los tribunales franceses (en las alegaciones del Ministerio Fiscal puede verse un buen resumen de estas), y derecho internacional, la STEDH acerca de los farmacéuticos franceses. Es preciso diferenciar entre la aplicación de uno y otro derecho, controvertido el primero

14. Con los interrogantes que ello acarrea. Por ejemplo, aunque estemos ante el contenido esencial de un derecho fundamental, ¿̇solo cabe su ejercicio bajo un presupuesto antiabortista? De ser así, ¿ello no delimita excesivamente el ámbito de validez material de un derecho fundamental (pues este no podría protegerse en cualquier relación jurídica de nuestro ordenamiento)? Y si el problema es la generalidad de situaciones en las que podría ejercerse este derecho, jes que el presupuesto antiabortista no puede justificarse sobre el respeto del derecho a la vida y no así del de la objeción de conciencia? 
y obligatorio el segundo, para después buscar un encaje teórico al no uso del derecho extranjero. Entendemos que un mismo modelo teórico de diálogo judicial debe permitirnos explicar las razones para usar y, al mismo tiempo, para no hacer uso el derecho extranjero.

\section{Diferencia entre el derecho internacional y el derecho extranjero}

En nuestro ordenamiento jurídico, la atención al derecho internacional tiene carácter obligatorio en virtud del artículo 10.2 CE, en la interpretación de los derechos fundamentales, los tratados internacionales sobre la materia ratificados por España son vinculantes: se establece el denominado canon interpretativo o hermenéutico para la interpretación de los derechos fundamentales ${ }^{15}$. De existir alguna norma internacional, ratificada y relativa a la objeción genérica de conciencia, nuestra constitución debe interpretarse en concordancia.

En el caso de este derecho, la obligatoriedad viene dada de forma indirecta. Ni la CE ni el CEDH contemplan expresamente la objeción de conciencia ${ }^{16}$, sino que este derecho ha sido reconocido en ambas jurisdicciones como una de las posibles manifestaciones de la libertad de pensamiento y de conciencia. Debemos preguntarnos por el alcance de esta obligación cuando las garantías de derechos equivalentes, proclamados en diferentes normas, están desarrolladas asimétricamente en una y en otra jurisdicción.

Tal es el caso que se plantea en la STC 145/2015 con el paso de la disposición a la dispensación. El TC resolvió una nueva situación al no haber pronunciamientos previos en el derecho internacional. De no haber considerado otro presupuesto, la decisión del TEDH hubiera tenido fuerza vinculante.

A diferencia del uso del derecho internacional, el extranjero, como el francés, no tiene el mismo carácter. El uso del derecho extranjero ha sido denominado «uso no autoritativo" al no existir ningún tipo de obligación o autoridad para aparecer en la decisión de un tribunal constitucional ${ }^{17}$.

En el caso que da lugar a la STC 145/2015, los tribunales ordinarios asentaron su decisión mediante el derecho internacional y el derecho extranjero, en este último caso las decisiones de los tribunales franceses que dan origen a la STEDH. Se advierte de este modo un uso autoritativo (STEDH) y un uso no autoritativo (decisiones de los tribunales franceses) relativo al derecho a la objeción de conciencia. A partir de este hecho, podemos realizar algunas observaciones: que el TC no invalidó ninguno de los dos usos (autoritativo y no autoritativo); y que ambos usos contribuyeron a formar la base de la argumentación de los tribunales ordinarios.

15. Aparicio Pérez, 1989: 9-18 y Roldán Barbero, 2012: 179-234.

16. No así la CDFUE, que lo incorpora en su contenido, y en virtud del mismo artículo $10.2 \mathrm{CE}$ es una norma sobre la materia y, por tanto, de obligada observancia en la interpretación de este derecho, aunque este asunto ahora excede del objeto del trabajo.

17. Para un resumen de esta postura, $c f r$. Filippini, 2007: 191-202. 
En primer lugar, al no existir una invalidación expresa del TC del uso no-autoritativo del derecho extranjero, podemos afirmar que estamos ante una de las posibles herramientas que los tribunales pueden emplear en la argumentación.

Y, en segundo lugar, tanto el uso autoritativo como el no autoritativo contribuyen a fundamentar la decisión del tribunal. Prueba no ser un uso inválido, sino una de las posibles herramientas argumentativas; su función no puede ser otra que la de adoptar decisiones más perspicuas, tal y como ha defendido recientemente la doctrina.

\section{El valor atribuido al derecho extranjero por el TC}

En cualquier modelo teórico de diálogo judicial, observamos el papel del derecho extranjero en la decisión judicial como una razón más para adoptar la decisión. Contribuye a formar la base de la justificación de la misma. Y con ello no podemos afirmar que el uso de derecho extranjero implique, o presuponga, aplicar una norma extranjera en la resolución de un caso.

Al prestar atención a cómo los tribunales ordinarios del caso emplean el derecho extranjero en sus decisiones, en ningún momento este derecho pasa a configurar la premisa mayor del silogismo que siguen los tribunales para llegar a una conclusión en su juicio considerado. De aparecer en esa premisa mayor del silogismo, se estaría aplicando una norma distinta a la propia constitución y quedaría en entredicho el autogobierno del TC.

El derecho extranjero no condiciona directamente la aplicación de la norma, sino que aporta razones para determinar la ratio decidendi del caso, esto es, contribuye a formar la base de la decisión del tribunal acerca de la materia de la constitución que está sometiendo a su conocimiento. De este modo, el derecho extranjero aparece dentro del conjunto de "consideraciones necesarias» que lleva a cabo el tribunal para poder «justificar»su decisión ${ }^{18}$. Este derecho aporta más razones a la argumentación y la interpretación de la propia constitución, al emplear justificaciones utilizadas en preceptos similares, o equivalentes, por parte de un tribunal extranjero. Es el propio tribunal quien considera necesario contemplar este derecho en la justificación de su decisión. De ahí no podemos afirmar el carácter vinculante del derecho extranjero: la relevancia la otorga el propio tribunal al aparecer en la ratio decidendi.

Aunque el TC hizo referencia al derecho extranjero e internacional en la STC $145 / 2015$, su alusión aconteció en la reconstrucción de los hechos, en el reflejo de las decisiones de los tribunales ordinarios y en las alegaciones de la fiscalía. La referencia circunstancial no constituyó una razón que fundamenta la decisión del tribunal. El TC se apartó de los precedentes, configuró su decisión a partir de otro presupuesto

18. Esta es la noción de ratio decidendi que aparece, entre otras, en las obras de Chiassoni, 2012: 222-225, Igartua, 2006, IturRalde, 2014: 195, y NúŃEZ Vaquero, 2016: 131. 
y, de este modo, se desvinculó del derecho extranjero o internacional. En este caso, el derecho extranjero debemos considerarlo obiter dictum.

Debemos asumir que una referencia circunstancial no nos permite considerar la aparición del derecho extranjero en la sentencia como una muestra de diálogo judicial. Por el contrario, hablaremos de diálogo judicial cuando la ratio decidendi del tribunal se configure a partir de elementos de derecho extranjero.

En síntesis, en el diálogo judicial, el uso del derecho extranjero se da en la ratio decidendi. Cuando este derecho aparece citado circunstancialmente en la decisión del tribunal, no supone ninguna razón para decidir en un determinado sentido. En esos casos no se emplea stricto sensu este derecho.

La distinción entre ratio decidendi y obiter dictum nos será de utilidad durante los próximos epígrafes, con el fin de evaluar los distintos modelos teóricos de diálogo judicial.

\section{Incompatibilidad del modelo de la resistencia}

De acuerdo con el modelo teórico de la resistencia, el uso del derecho extranjero plantea un problema de soberanía judicial, o de autogobierno, al que aspiran las democracias constitucionales. Según sus defensores, se introduce una complejidad innecesaria en la justificación de las decisiones judiciales y se dificulta el desarrollo de una cultura constitucional diferenciada ${ }^{19}$.

Este modelo teórico nos parece incompatible tanto con el uso como con el no uso del derecho extranjero. Al menos, por dos motivos: 1) porque la potestad de aplicar las propias normas es una condición necesaria del autogobierno; y 2) porque al aparecer en la ratio decidendi, el uso del derecho extranjero no equivale a aplicar una norma extraña al propio ordenamiento jurídico.

En modelos de Estado con constituciones rígidas y con control judicial de constitucionalidad de las leyes necesariamente asumimos que la potestad para aplicar la propia constitución constituye una condición del autogobierno. En otras palabras, el tribunal constitucional de un Estado es el encargado del control de constitucionalidad de las leyes porque es el encargado de aplicar su constitución. Carecería de sentido que fuese un tribunal completamente ajeno al Estado el que tuviera esta potestad. De ser así, un tribunal ostentaría el poder de ser el máximo intérprete de la constitución y otro tribunal tendría la potestad de controlar la constitucionalidad de las leyes y, por tanto, también podría controlar la actividad del intérprete máximo de la constitución, que por su parte podría volver a interpretar la constitución en un sentido distinto al previamente establecido, generando así un círculo interminable.

$\mathrm{Al}$ ser los mismos tribunales constitucionales los máximos intérpretes de sus constituciones, a su vez son quienes controlan la constitucionalidad de las leyes. Con ello

19. Rosenkrantz, 2003: 277.

Doxa. Cuadernos de Filosofía del Derecho, (2020), 43, pp. 313-339 
observamos que este modelo teórico resulta inconsistente por las siguientes razones: a) únicamente el tribunal nacional tiene la potestad de aplicar la constitución de ese Estado; b) lo que este tribunal aplica es su propia constitución y no cualquier otra norma; c) un tribunal extranjero no aplica la constitución del Estado; d) el tribunal extranjero aplica una norma que no le permite realizar el control de constitucionalidad de ese Estado.

Como vimos, el fenómeno del diálogo judicial no implica que se cree un vínculo preceptivo con la jurisprudencia de un tribunal extranjero. Una explicación más extensa del anterior punto «b)» y la distinción entre los dos tipos de aplicación del derecho que encontramos en DwORKIn pueden sernos de ayuda para terminar de esclarecer las razones de esta inconsistencia.

A través del diálogo judicial, el tribunal de un Estado incorpora el derecho extranjero en el plano justificativo de la norma, no en el de adecuación ${ }^{20}$. El tribunal se ayuda del derecho extranjero para tomar una decisión que no puede ser concluyente desde el ámbito de la adecuación sino de la fundamentación. Y se ayuda para formar la base de su razonamiento. Entonces se patentiza que no es una cuestión de autogobierno: el tribunal emplea el derecho extranjero para decidir en un sentido determinado, sin que se aleje de un mismo marco común de principios y valores, y sin aplicar una norma distinta a su propia constitución.

Además, constituye una óptima justificación externa de la decisión, en tanto que permite controlar la adecuación y la solidez de las premisas constitucionales sobre las que decide el tribunal ${ }^{21}$. Este uso del derecho extranjero no nos plantea ningún problema de autogobierno, sino que, al contrario, contribuye a consolidar la interpretación sobre la propia constitución.

\section{Imposibilidad de justificar el modelo de la convergencia}

Según el modelo teórico de la convergencia, las prácticas judiciales están destinadas a converger mediante el derecho internacional y el de otras jurisdicciones. De forma gráfica, este modelo ha sido descrito como una suerte de "tribunal de Babel», en el que el lenguaje jurídico común sería el eje de la convergencia ${ }^{22}$. De ser cierta esta teoría, deberíamos poder sostenerla, en algún grado, a través de las decisiones que incorporan derecho extranjero.

La sentencia sobre la objeción de conciencia nos presenta algunos puntos de interés para sostener este modelo, entre los cuales destacamos: 1) tanto el TC como el TEDH se pronunciaron sobre la posibilidad de garantizar el derecho genérico a la objeción de conciencia; y 2) la fundamentación de estos tribunales coincide en que es

20. DwOrkin, 1984: cap. IV.

21. Y que se justifica en los «elementos constitucionales esenciales», como tratamos de mostrar en el epígrafe 4.iii.

22. Cassese, 2009: 12 y ss. 
parte del contenido esencial del derecho a la libertad de pensamiento, equivalente a nuestro derecho fundamental a la libertad ideológica, tratándose de una de sus posibles manifestaciones.

Ciertamente, ambos tribunales han tenido que hacer frente a la misma realidad: existen diferencias entre el mínimo ético que caracteriza un comportamiento exigido por ley, y que por tanto está respaldado por la mayoría, y el mínimo ético que un ciudadano en minoría defiende que el Derecho debería respaldar a través de esa obligación. La cuestión reside en decidir si prevalece el derecho de esa minoría en un caso concreto.

A través de la clásica ponderación judicial se desarrollan las garantías del derecho a la objeción de conciencia. Y aquí podemos encontrarnos ante garantías que estén desarrolladas con mayor amplitud en la jurisprudencia nacional en comparación al foro internacional. De ser cierto el modelo teórico de la convergencia, la práctica judicial del TC debería tender a homogeneizarse con la del resto de tribunales extranjeros e internacionales. En un primer momento, las garantías más desarrolladas en su propia jurisdicción no supondrían un problema para este modelo en cuanto estarían previstas para situaciones aún no resueltas por otros tribunales.

Hasta aquí podríamos justificar este modelo teórico. Incidamos ahora nuevamente sobre el no uso del derecho extranjero llevado a cabo por el TC.

El TEDH y los tribunales franceses habían considerado anteriormente que dos farmacéuticos franceses, ambos titulares de un establecimiento farmacéutico, no pueden ejercer el derecho a la objeción de conciencia para eximirse de la obligación de dispensar medicamentos antiabortivos. Si consideramos que tanto la sanción administrativa como las condenas de los tribunales ordinarios al farmacéutico hispalense procedían de una inspección originada con la fallida dispensación de un producto farmacéutico, los casos atendidos por el TC y el TEDH tendrían idéntico origen.

Deberíamos poder inferir la convergencia, si además consideramos que el TC no cuestionó el uso de los precedentes por parte de los tribunales ordinarios, sino que se centró en justificar el presupuesto de la disposición. De la decisión del TC no podemos extraer que el uso del derecho extranjero e internacional no pueda producirse al omitir pronunciarse al respecto. Es una cuestión asumida por el propio TC: si existen precedentes, esto es, decisiones en casos similares como los resueltos por los tribunales franceses y el TEDH, es algo habitual que los tribunales los traigan a colación en sus decisiones.

Ahora bien, pese a todo lo anterior, el TC pudo apartarse de los precedentes y tomar una decisión contraria: atendió otros aspectos del caso que consideró relevantes y pudo atribuir una solución normativa distinta. En definitiva, el uso del derecho extranjero cristalizó en una opción válida para los tribunales en el momento de resolver el caso. Esto es, como un instrumento del que disponen en su argumentación y sobre el que nos resulta imposible verificar las premisas de la convergencia a raíz de la decisión contraria a los precedentes.

Con la STC 145/2015 no podemos sostener este modelo. Las decisiones del TC y del TEDH presentan soluciones normativas distintas para lo que se presenta como un mismo supuesto. Y es que en Francia se dispensarán determinados medicamentos, 
aunque lidien motivos de conciencia, mientras que en España no, porque esos mismos motivos tienen validez en un instante previo a ese supuesto.

En alguna medida, dicha convergencia debería haber repercutido en la decisión del TC. Al apartarse del precedente vinculante del TEDH, el TC evidenció que la tradición jurídica de cada Estado tiene demasiado peso en la práctica judicial como para no ser considerada más seriamente en el modelo teórico de la convergencia. De ser un modelo correcto, el TC hubiera encontrado motivos insuperables, o mayor resistencia, que le hubieran impedido la omisión de pronunciarse al respecto de los mismos.

\section{La fundamentación que hace válido el modelo de la imbricación}

Descartados los modelos teóricos de la resistencia y de la convergencia para dar explicación del no uso del derecho extranjero, nos centraremos en la explicación del modelo teórico de la imbricación que nos permite dar respuesta al no uso de este derecho según lo acontecido en la STC 145/2015. Para ello, debemos prestar atención a la propuesta del equilibrio reflexivo amplio, diferenciando entre el equilibrio reflexivo amplio y el estrecho, analizando la diferencia entre las garantías del derecho a la objeción de conciencia en el marco teórico-moral propio del Estado y en el que se adhiere el mismo, y exponiendo la relación entre la razón pública y la ratio decidendi.

\section{i. Distintos equilibrios reflexivos}

Además de la distinción entre obiter dictum y ratio decidendi, podemos realizar otra distinción en el uso del derecho extranjero por parte de los tribunales, según si contribuye a realizar una justificación de mayor o menor exigencia. La decisión judicial también se justifica prestando atención al marco teórico y moral global al que se adscribe el Estado. En ese marco, la justificación será más exigente.

John Rawls (1999: 40 y ss.) denominó equilibrio reflexivo amplio a buscar la justificación de una decisión en un contexto teórico más exigente que el propio. Por el contrario, cuando la decisión de un tribunal se justifica en el propio marco teórico moral del Estado es cuando dicha actividad recibe la denominación de equilibrio reflexivo estrecho.

En la STC 145/2015, el caso pasó de buscar una solución mediante el equilibrio reflexivo amplio a decidirse a través del equilibrio reflexivo estrecho. Cuando los tribunales ordinarios construyeron la base de su decisión considerando las decisiones del TEDH y los tribunales franceses, el equilibrio reflexivo fue amplio. Se recurrió a un contexto justificativo más exigente que el propio para asentar la decisión. Finalmente, el TC decidió el caso a través de un presupuesto sobre el cual no había ningún precedente en el derecho extranjero. Consideró que sí existía un precedente interno, de 1985, sobre la posibilidad de que un médico ejerciera el derecho a la objeción de conciencia por motivos antiabortistas. Buscó así la justificación en su propio marco teórico-moral. 


\section{ii. Diferentes garantías en diferentes marcos teórico-morales}

Con la decisión del TC se generó confusión acerca del alcance de este derecho al extender el presupuesto antiabortista de objeción de los médicos a los farmacéuticos. Se justificó la decisión en el propio marco teórico y moral; el TC hizo valer un argumento analógico para crear una solución normativa contraria a los precedentes.

Si con esa decisión el TC pretendía garantizar un posicionamiento ideológico concreto, en este caso el antiabortista, no hubiera sido necesario ni evitar pronunciarse sobre el derecho extranjero ni extender por analogía un precedente de hacía treinta años. Y ello es así porque la STEDH, de carácter vinculante, aplica un derecho sobre el que pocas veces ha tenido la oportunidad de pronunciarse: el derecho genérico a la objeción de conciencia en conflictos éticos del ámbito de las ciencias biomédicas. La STEDH sobre los farmacéuticos franceses fue la primera de ese tribunal en un ámbito distinto al castrense.

Contrariamente, en el caso español contamos con una jurisprudencia reiterada acerca de la existencia del derecho genérico a la objeción de conciencia ${ }^{23}$. Ciertamente, las garantías de este derecho están desarrolladas más ampliamente en nuestra jurisprudencia que en la europea o la extranjera.

Por esta razón, en sede del equilibrio reflexivo amplio, el TC podría haber acudido a una solución contraria a la del TEDH y de los tribunales franceses sin apartarse de sus decisiones y sin realizar una argumentación tan conflictiva. El equilibrio reflexivo torna una justificación más perspicua (MORESO, 2018), incluso aquellas que deciden a contrario sensu del precedente invocado por razones como un mayor número de garantías a nivel interno.

De haber considerado el mismo presupuesto que daba pie al pronunciamiento del resto de tribunales (nacionales, extranjeros e internacionales), el TC hubiera tenido que justificar el cambio de criterio explicando por qué las garantías de ese derecho tienen mayor rango de validez material en su jurisdicción y, en definitiva, concediendo de este modo mayor claridad a su decisión.

Pese a su decisión, el uso del derecho extranjero por parte de los tribunales inferiores no dejó de ser un recurso argumentativo válido. No se cuestionó el modelo teórico de la imbricación, antes encontramos un reconocimiento implícito del mismo, puesto que, en términos justificativos, el equilibrio reflexivo amplio buscado por los tribunales ordinarios no es lo que invalidó la sentencia del TC, sino la solución normativa. Aunque el TC pasó del equilibrio reflexivo amplio al estrecho, no desvirtuó el modelo teórico de la imbricación, y por ello consideramos que el mismo sale reforzado.

Si ciertamente las prácticas de los tribunales estuvieran destinadas a converger, el TC se hubiera visto vinculado en algún grado por la decisión del TEDH. Hubiera empleado un argumento el cual podríamos considerar «a fortiori» ${ }^{24}$, pues con mayor

23. Vid. N.P. 2.

24. Moreso, 2016: 150-151.

Doxa. Cuadernos de Filosofía del Derecho, (2020), 43, pp. 313-339 
razón si en un precedente se atribuye tal solución al caso de los farmacéuticos franceses, deberá atribuírsele al caso de los españoles. El TC no hubiera atribuido una solución normativa distinta a lo que fin de cuentas es el mismo supuesto, esto es, que no se dispensen medicamentos por motivos de conciencia.

En resumen, aunque el TC no se mostró contrario a la justificación de los tribunales ordinarios, tampoco buscó el equilibrio reflexivo en las garantías más desarrolladas de su propio marco teórico-moral, el cual podría haber justificado que era más exigente (por más desarrollado). Ciertamente, al evitar pronunciarse sobre la decisión de aquellos tribunales, el TC evitó al mismo tiempo invalidar el recurso al derecho extranjero y europeo.

Y aunque el TC hubiera decidido en este mismo sentido escudándose en unas garantías más desarrolladas en su jurisdicción, tampoco hubiera invalidado el modelo teórico de la imbricación y las premisas del equilibrio reflexivo amplio, pues el respeto a la tradición jurídica de un Estado tiene cabida dentro de este modelo teórico.

\section{iii. Razón pública y ratio decidendi}

La explicación teórica del equilibrio reflexivo amplio se ayuda del concepto de razón pública con el fin de filtrar las opiniones que alcanzan el foro público. El concepto de razón pública rawlsiano nos permite encajar la teoría del equilibrio reflexivo amplio en lo expuesto sobre la ratio decidendi, esto es, en el modo en que aparece el derecho extranjero en las decisiones judiciales.

Para NúNEEZ VAQUero, el carácter vinculante de las razones que se invocan para justificar una decisión, y que por tanto aparecen en la ratio decidendi de un tribunal, tiene el problema de no poder filtrar las razones más relevantes, dado que, en principio, todas las disponibles deberían serlo. El autor lo explica de la siguiente manera:

«¿Cuáles son el conjunto de todas las consideraciones que debemos considerar como «necesarias»? ¿todas aquellas cuya modificación implicarían un cambio de la decisión final? Establecer cuáles son las consideraciones necesarias de la decisión genera no pocos problemas.

En primer lugar, desde el punto de vista empírico, no resulta muy plausible afirmar que son todas y cada una de las razones que forman parte de la justificación externa de la sentencia las que resultan vinculantes ${ }^{25}$.

De aquí observamos que esta cuestión consta de dos partes: 1) que el derecho extranjero constituya una razón necesaria para decidir el caso; y 2) que configure la justificación externa de la sentencia.

La posibilidad de afirmar que el derecho extranjero configura todas las razones necesarias para contribuir de manera decisiva en la decisión final del tribunal no es menos que una quimera, al menos si otorgamos valor absoluto a todos los argumentos

25. NÚNEZ VAQUeRo, 2016: 132.

Doxa. Cuadernos de Filosofía del Derecho, (2020), 43, pp. 313-339 
que pueden ser determinantes en la decisión. Es aquí cuando debemos recurrir a la noción de razón pública rawlsiana empleada por Moreso (2018: 84-88) para explicar el equilibrio reflexivo amplio en el diálogo judicial, que nos ofrece una respuesta a ambas cuestiones.

No todos los argumentos pueden ser válidos, solo aquellos que bajo el criterio de la reciprocidad pueden introducirse en el foro público y cuando aludan expresamente a «elementos constitucionales esenciales». El uso del derecho extranjero no puede excluirse si necesariamente contribuye a que el tribunal justifique su decisión sobre esos elementos. Como el concepto de diálogo judicial aparece en el contexto interpretativo de la constitución de un Estado, el uso del derecho extranjero supone un mecanismo legítimo dentro de los parámetros establecidos por la razón pública.

Al mismo tiempo, la noción de razón pública nos ofrece razones para responder a la segunda parte del problema. Para que un argumento proceda justificado externamente, debemos prestar atención a la solidez de las premisas normativa y fáctica. Hemos descartado que el derecho extranjero constituya la adecuación de la premisa normativa, al ser la propia constitución la norma aplicable al caso que trata de resolver el tribunal. En consecuencia, debemos ofrecer razones que despejen las dudas en torno a la premisa fáctica.

Aquí nos surge un problema de calificación ${ }^{26}$ porque no podemos estar seguros de que el derecho extranjero al que acude el tribunal pueda ser calificado según la propia constitución. Siguiendo a Alchourrón y Bulygin (1971: 31-34), estaríamos frente a un problema de subsunción: el caso particular invocado por el tribunal no sabemos si pertenece, como instancia particular, al caso genérico que se contempla en la constitución. Hay muchos hechos del caso extranjero que el tribunal no puede conocer y su desconocimiento empírico sería la causa de la dificultad en la calificación o el encaje constitucional del caso invocado. De ser así, estaríamos ante una «laguna de conocimiento ${ }^{27}$. ¿El derecho extranjero constituye una instancia particular del caso genérico que prevé la constitución? Creemos que existen razones sólidas para sostener una respuesta afirmativa.

La primera sería que tanto el Estado nacional como el extranjero son modelos de democracia constitucional, con control judicial de constitucionalidad de las normas y, por consiguiente, adheridos a un marco teórico común de principio y valores. Y, la segunda, que el diálogo judicial como expresión de la razón pública tiene carácter restrictivo: su utilidad se evidencia en aquellos Estados configurados como una democracia constitucional y en cuestiones relativas a "elementos constitucionales básicos», o lo que es lo mismo, a instancias particulares de casos genéricos que de algún modo aluden las constituciones de toda democracia constitucional.

26. No así algún problema de veracidad de la proposición de la premisa, dado que el derecho extranjero que considera un tribunal suele citarse expresamente en su argumento. No es habitual que un tribunal haga referencia a la argumentación de una sentencia, nacional o extranjera, sin identificarla de algún modo. Por tanto, al citar la sentencia extranjera se despeja cualquier cuestión relativa a a veracidad de la proposición.

27. Alchourrón y Bulygin, 1971 y Moreso y Vilajosana, 2004: 110-111. 
Según esta explicación, el uso del derecho extranjero en la ratio decidenci contribuiría necesariamente a la justificación de una decisión y constituiría además una justificación externa adecuada de la premisa fáctica. El tribunal constitucional que hace uso del derecho extranjero no está aplicando otra norma, sino que recurre a ella para justificar la aplicación de la propia constitución.

A nuestro juicio, todo ello termina por consolidar las premisas sobre las que se ha considerado el equilibrio reflexivo amplio como la correcta fundamentación del modelo teórico de la imbricación. En efecto, aunque no sean vinculante para el TC, las fuentes y la experiencia del derecho extranjero constituyen elementos justificativos para tomar decisiones más perspicuas.

\section{CONCLUSIONES}

A través de la STC 145/2015 hemos sido testigos de que el alcance general del derecho genérico a la objeción de conciencia queda, en primer lugar, aparentemente reducido a un solo presupuesto, el antiabortista, y, en segundo lugar, ampliado por un ejercicio colectivo del mismo que más bien se corresponde con la imposición de ese mismo posicionamiento ideológico.

Por otro lado, acudir al derecho extranjero e internacional hubiera ayudado a consolidar la argumentación del TC asentando las buenas razones para decidir que se desprenden del derecho español al respecto del derecho genérico a la objeción de conciencia. Tanto por las razones del TC para no hacer uso del derecho extranjero como por el modo en que se produce el mismo, llegamos a la conclusión de que el único de los tres modelos teóricos de diálogo judicial que resulta compatible es el de la imbricación. Y resulta así porque el uso y el no uso del derecho extranjero se justifican adecuadamente en buscar el equilibrio reflexivo de la decisión.

A través del equilibrio reflexivo amplio, el derecho extranjero aparece como razones que configuran la base de la decisión del tribunal, por lo que incardinamos su aparición en las decisiones judiciales dentro de la ratio decidendi. De ahí no podemos deducir que este uso se corresponda con aplicar una norma diferente a la propia constitución o con que otro tribunal sea quien decida el caso. Con el diálogo judicial, en definitiva, no se compromete el autogobierno de los propios tribunales de un Estado. Los tribunales pueden hacer o no hacer uso del derecho extranjero, lo que tampoco comulga con la tesis que vaticina una práctica unitaria de los tribunales, por la que terminaría ignorándose la tradición jurídica propia de cada Estado.

Aun en casos de no uso del derecho extranjero, el modelo teórico de la imbricación se erige como la explicación teórica apropiada para el fenómeno al que nos referimos por diálogo judicial. Para ello debemos advertir que las explicaciones del equilibrio reflexivo amplio junto a la noción de razón pública constituyen genuinamente su correcta fundamentación. 


\section{BIBLIOGRAFÍA}

Alchourrón, C. E. y Bulygin, E., 1971: Normative Systems, Library of Exact Philosophy, Nueva York.

Atienza, M., 1986: Sobre la analogía en el derecho, Civitas, Madrid.

Aparicio Pérez, M.A., 1989: «La cláusula interpretativa del artículo 10.2 de la Constitución Española, como cláusula de integración y apertura constitucional a los derechos fundamentales», Jueces para la democracia, núm. 6.

Aparicio Tovar, J., 1980: «Relación de Trabajo y libertad de pensamiento en las empresas ideológicas», en Lecciones de Derecho del Trabajo en homenaje a los Profesores Bayón Chacón, Universidad Complutense, Madrid.

CASSESE, S., 2009: I tribunali di Babele. I giudici alla ricerca di un nuovo ordine globale, Donzelli, Roma.

Chinssoni, P., 2004: «Il precedente giudiziale: tre esercizi di disincanto», Analisi e diritto, Marcial Pons.

Díez-Picazo, L.M., 2013: Sistema de derechos fundamentales, Civitas, Pamplona.

Dworkin, R., 1984: Los derechos en serio, Ariel, Barcelona.

Escobar Roca, G., 1993: La objeción de conciencia en la constitución española, Centro de estudios constitucionales, Madrid.

Filippini, L., 2007: «El derecho internacional de los derechos humanos no es un préstamo: reflexiones sobre la crítica a los préstamos de Carlos F. Rosenkrantz», Revista Jurídica de la Universidad de Palermo, Año 8, núm. 1, Buenos Aires.

García de EnTERría, E., 1974: La lucha contra las inmunidades del poder, Civitas, Madrid.

Gascón Abellán, M., 1990: Obediencia al derecho y objeción de conciencia, CEPC, Madrid.

González Pérez, J., 2017: La dignidad de la persona, Civitas, Pamplona.

GonzÁlez SAQuero, P., 2008: «¿Derecho a la objeción de conciencia del farmacéutico?», Nueva Época, núm. 8.

IgArtuA, J., 2006: La fuerza vinculante del precedente judicial», Isegoría, núm. 35.

Iturralde, V., 2004: «Precedente judicial», Eunomía, núm. 6.

Moreso, J.J., 2016: Lógica, argumentación e interpretación del derecho, UOC, Barcelona.

Moreso, J.J., 2018: «El diálogo judicial como equilibrio reflexivo amplio», Anuario de Filosofía del Derecho, tomo XXXIV.

Moreso, J.J. y Vilajosana, J.M., 2004: Introducción a la teoría del derecho, Marcial Pons, Barcelona.

Navarro, P.E., 1990: La eficacia del derecho; Centro de Estudios Políticos y Constitucionales, Madrid.

Navarro, P.E. y Moreso, J. J., 1996: «Aplicabilidad y eficacia de las normas jurídicas», Isonomía, núm. 5.

Navarro-Valls, R. y Matínez Torrón, J., 2011: Conflictos entre conciencia y ley. Las objeciones de conciencia, Iustel, Madrid.

NúÑEZ VAQUERO, Á., 2016: «Sin precedentes: una mirada escéptica a la regla del stare decisis», DOXA, núm. 39.

Prieto SANChís, L., 2013: El constitucionalismo de los derechos; Trotta, Madrid.

Rawls, J., 1999: A theory of justice, Harvard University Press, 2. ${ }^{a}$ Edición. 
RoldÁn BARbero, J., 2012: «Jurisprudencia española en materia de Derecho internacional púbico», REDI, Vol. 64, núm. 1.

Rosenkrantz, C.F., 2003: «Against borrowings and other nonauthoritative uses of foreign law»; International Journal of Constitutional Law, Oxford University Press and New York University School of Law.

Ruiz Miguel, A., 1986-1987: «Sobre la fundamentación de la objeción de conciencia», Anuario de Derechos Humanos, UCM, núm. 4. 